\title{
A Traffic Prediction for Intelligent Transportation System using Machine Learning
}

\author{
V.Geetha, C K Gomathy, T. Harshitha, P. Vijay Nagendra Varma
}

\begin{abstract}
Traffic control has been an issue for a long time from the past. The modern world demands Technology. Now a days cars are one of the main methods of improvement in technology. Intelligent Traffic System is also known as Intelligent Transportation System apply communication and information technology to find the solution for the Traffic control issues. Intelligent Transportation System represents the main problem in transportation. ITS is a program .it is used to improve the efficiency of transportation through advanced technologies by using sensors and communication. Some of the problems like Traffic congestion, Low safety can be solved through this Intelligent Transportation System by Using the Latest techniques in traffic management.ITS is improved by using wireless and wireline communication-based information, control and electronic technologies. Now a days overspeeding is a key issue in the traffic control system to overrule the issue. Dophler Phenomenon is used for speed measurement.
\end{abstract}

Keywords: Traffic Environment,Genetic algorithm,Machine Learning,Big Data,Image Processing.

\section{INTRODUCTION}

Intelligent transportation system is used for analyzing the information. ITS is used to control communication technologies for road transportation to improve safety and efficiency. Intelligent transportation system includes a wide range of applications which is used to get information, to control congestion, to improve traffic management, to reduce the environmental effects and increase the benefits of transportation. ITS refers to the different types of needs and the transport field with many others policing. But also due to lessconnection of traffic flow. Smartphones having different sensors.it can be used to detect/track the traffic speed and density.

Manuscript received on April 07, 2021.

Revised Manuscript received on April 15, 2021.

Manuscript published on April 30, 2021.

*Correspondence Author

Dr. V. Geetha, Assistant Professor, Computer Science and Engineering Department, SCSVMV Deemed to be University, Kanchipuram, Tamil Nadu.

Dr. C K Gomathy*, Assistant Professor in Computer Science and Engineering Department, SCSVMV Deemed to be University, Kanchipuram, Tamil Nadu.

T. Harshitha, Computer science and engineering Department, SCSVMV Deemed to be University, Kanchipuram, Tamil Nadu.

P. Vijay Nagendra Varma, Computer science and engineering Department, SCSVMV Deemed to be University, Kanchipuram, Tamil Nadu.

(C) The Authors. Published by Blue Eyes Intelligence Engineering and Sciences Publication (BEIESP). This is an open access article under the CC BY-NC-ND license (http://creativecommons.org/licenses/by-nc-nd/4.0/)
Now a days, smartphones are used by drivers and it is monitored to detect the speed of traffic and quality of the road. Data is connected through the audio and GPS .it tracks the identity of traffic and possible jams occurred in the traffic.

\section{LITERATURE SURVEY}

The review process is divided into five stages to find the process in a simple and adaptable way.

It is necessary to start with a particular domain of any division/city of interest and it causes a specific problem. Literature also tells us that AVs would reduce vehicle ownership, travel timing, parking lots, and emissions It is also telling that AVs would increase the road capacity, traffic flow stability, vehicle miles travelled, fuel efficiency and safety. The ACC (Adaptive Cruise Control) can perform total control of the vehicle byfocussing on the speed without any data from the driver/conductor.

\section{PROPOSED METHODOLOGY:}

Any technique that uses information and control technologies can be divided into small functions:
A. Collection of Data
B. Processing of Data
C. Decision Making System

Arrangement and inspection support based on information. Multiple forms of wireless communication technologies have been introduced for the intelligent transportation system. Communications of radio modem on UHF and VHF frequencies are highly used for short and long-range communication in transportation system.

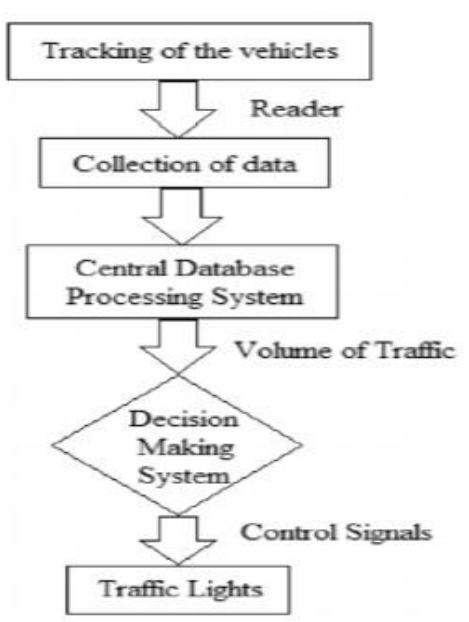

Fig 1: Tracking the Vehicle

Published By:

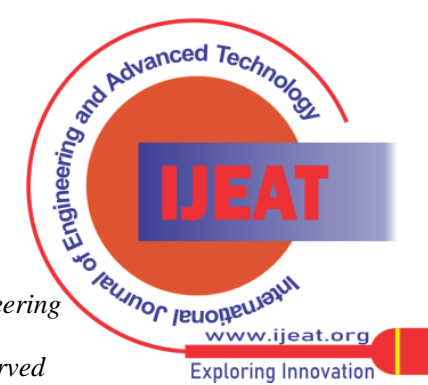

Blue Eyes Intelligence Engineering \& Sciences Publication (C) Copyright: All Rights Reserved 


\section{A Traffic Prediction for Intelligent Transportation System using Machine Learning}

\section{It is focused Collection of Data:}

On the data which collects from the congestion area.it also involves the tracking of vehicles in lanes.in this the algorithm is independent.

\section{Processing of Data:}

There are so many possible lanes and data are automatically collected and observed and simplified the data and then send to different input and output signals and it is required by Traffic Light Algorithm.some of parameters which can include length,queue, inflow, and outflow

\section{TECHNOLOGIES USED}

The technologies used are:

$\rightarrow$ Sensing Technologies

$\rightarrow$ Inductive Loop Detection

$\rightarrow$ Car Floating Data/Car Cellular Data

$\rightarrow$ Wireless Communication

\section{Sensing Technologies:}

Sensing technologies have greatly enhanced the technical capabilities and safety benefits of its. These sensor technologies include inductive loop that can read the vehicles speed, the number of vehicles moving and also the size of the vehicles.

$\rightarrow$ Infrastructure Sensors

$\rightarrow$ Vehicle sensors

Wireless communications:

Intelligent Transportation system has been proposed various wireless communication systems. they are:

$\rightarrow$ short range wireless communications

$\rightarrow$ long range wireless communications

Inductive Loop Detection:

To detect the vehicles inductive loops are used and it is placed in roadside.it count the vehicles using simple detectors in one minute of time and also it can be placed in different number of lanes/junctions. In this the vehicles are going with high speed.

\section{Block Diagram:}

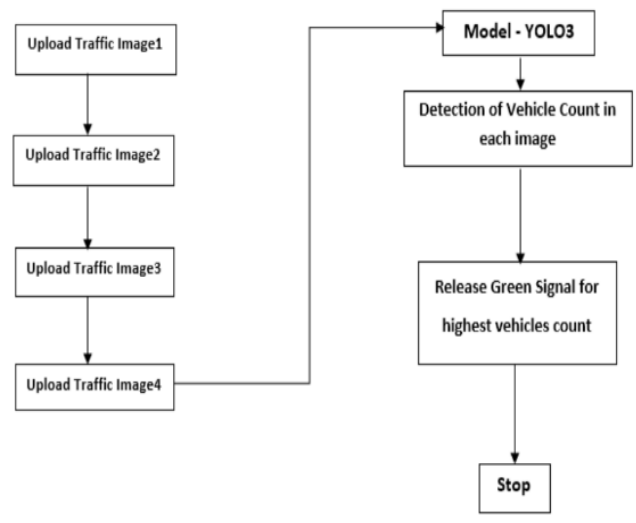

Algorithm:

Fig 2: Vehicles control flow

Step1: open the application
Step2: User have to upload 4 images in 4 traffic lanes one by one in the order.

Step3: After uploading of these images it goes to mode-YOLO3

Step4: It detects the no of vehicles are passing.

Step5: And also count.

Step6: Release Green signal for highest vehicles count.

Step7: So it is being processed under video surveillance

Step8: Stop

\section{WORKING PROCEDURE}

This project intends to designa system which uses deep neural network algorithm which is a subset of artificial intelligence,which will provide intelligence to the current traffic control system present at a four-way junction. This system is mainly aimed to replace the timer of traffic control system with artificial intelligence system. Nowadays most cities are equipped with CCTV cameras on the roads and the junctions, the basic idea is to collect the live video from the CCTV cameras and detect the number of vehicles on each lane and feed the data into another machine learning algorithm. according to the data of each lane changes into the light phase of the green signal. This system mainly aims to increase the traffic efficiency by increasing vehicle flow which will reduce waiting time for the vehicles

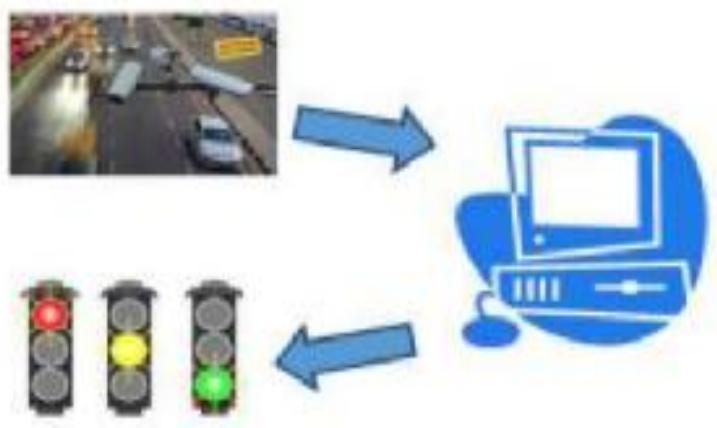

Fig 3: Traffic Signal Flow

\section{Detecting Vehicles:}

To detect the number of vehicles. For that we are using neural network algorithm as the basis of the design. Framework for the neural networks is must before starting to design the algorithm. We used Tensor Flow framework and Keras framework to create a neural network which will detect number of vehicles. A convolution neural network is used which is one type of neural network. The datasets will be fed into the designed neural network so to train the neural network in order to get highly accurate results.

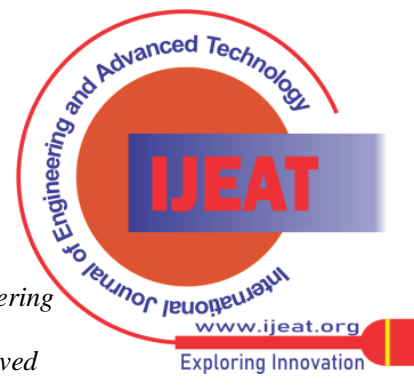




\section{RESULTS}
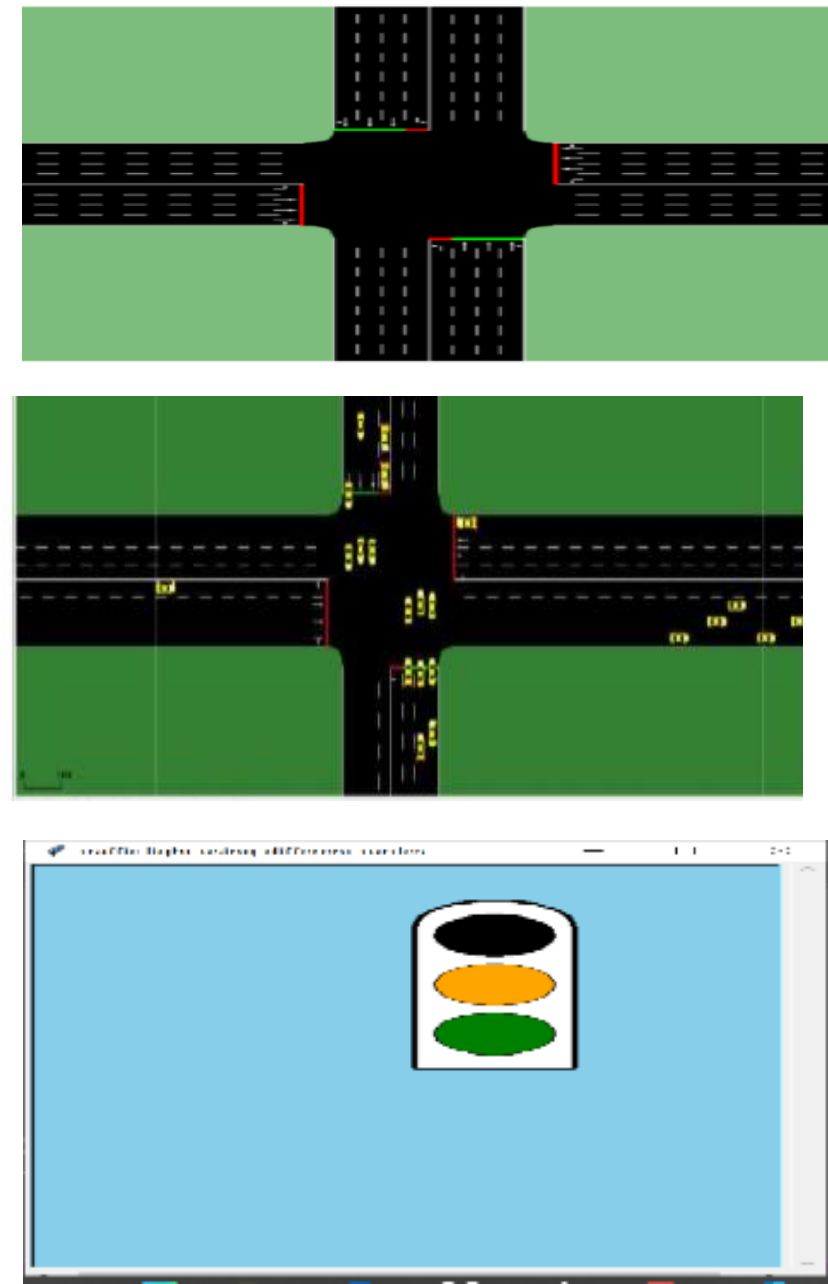

Fig 4: Four Lane Intersection

\section{CONCLUSION}

It is very important problem in data analysis. Here we are using deep learning and genetic algorithm. These proposed algorithm gives the much higher efficiency than the existing system. From the dataset it modifies the complex issues. So we have to planned to design the web server and web application. All algorithms are furtherly improved.

\section{REFERENCES}

1. Stevens, A (1996) Review of the potential benefits of road transport telematics, TRL Report 220. Crowthorne. TRL.

2. Accident Analysis and Prevention, $132,10522$. https://doi.org/10.1016/j.aap.2019.07.002

3. Vanajakshi L Real Time Identification of Inputs for a BATP System Using Data mining. DOI https://doi.org/10.1007/s40999-017-0210-y (2017)

4. Travel time prediction under different traffic conditions using global positioning system and its data come from buses. IET Intelligent Transportation Systems. 3(1), 1-9 (2009)

5. Hemalatha. C.Kand N. Ahmed Nisar (2011)., Explored teachers' commitment in self financing engineering colleges, International Journal of Enterprise Innovation Management Studies (IJEIMS), Vol2. No2. July-Dec 2011 ISSN: 076-2698 Retrieved from www.ijcns.com

6. Hemalatha. C.Kand N. Ahmed Nisar (2019)., A STUDY ON TEACHERS PROFESSION LOYALTY IN EDIFICATION IMPROVEMENT, Journal of Emerging Technologies and Innovative Research (JETIR) , JETIR June 2019, Volume 6, Issue 6, (ISSN-2349-5162)from etir.org/papers/JETIR1906W84.pdf

7. Dr.C K Gomathy, Article: The Efficient Automatic Water Control Level Management Using Ultrasonic Sensor, International Journal of

Published By: Blue Eyes Intelligence Engineering \& Sciences Publication
2020

8. C K Gomathy and V Geetha. Article: Evaluation on Ethernet based Passive Optical Network Service Enhancement through Splitting of Architecture. International Journal of Computer Applications 138(2):14-17, March 2016. Published by Foundation of Computer Science (FCS), NY, USA, ISSN No: 0975-8887

9. DR.C.K.Gomathy , V.Geetha , S.Madhumitha , S.Sangeetha , R.Vishnupriya Article: A Secure With Efficient Data Transaction In Cloud Service, Published by International Journal of Advanced Research in Computer Engineering \& Technology (IJARCET) Volume 5 Issue 4, March 2016, ISSN: 2278 - 1323.

10. C.K.Gomathy.(2010),"Cloud Computing: Business Management for Effective Service Oriented Architecture" International Journal of Power Control Signal and Computation (IJPCSC), Volume 1, Issue IV, Oct - Dec 2010, P.No:22-27, ISSN: 0976-268X

11. Dr.C K Gomathy, Article: A Semantic Quality of Web Service Information Retrieval Techniques Using Bin Rank, International Journal of Scientific Research in Computer Science Engineering and Information Technology ( IJSRCSEIT ) Volume 3 | Issue 1 | ISSN : 2456-3307, P.No:1563-1578, February-2018

12. Dr.C K Gomathy, Article: A Scheme of ADHOC Communication using Mobile Device Networks, International Journal of Emerging technologies and Innovative Research ( JETIR ) Volume 5 | Issue 11 ISSN : 2349-5162, P.No:320-326, Nov-2018.

13. Dr.C K Gomathy, Article: Supply chain-Impact of importance and Technology in Software Release Management, International Journal of Scientific Research in Computer Science Engineering and Information Technology ( IJSRCSEIT ) Volume 3 | Issue 6 | ISSN : 2456-3307, P.No:1-4, July-2018

\section{AUTHORS PROFILE}

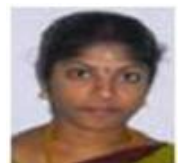

Dr.V.Geetha, is an assistant professor in compute science and engineering at Sri Chandrasekharendra Saraswathi Viswa Mahavidyalaya Enathur, Kanchipuram,India. Her area of intrest lies in Java Programming,Software Quality Assurance,Computer System Architecture Domain.

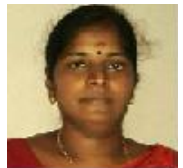

AssuranceIOT.
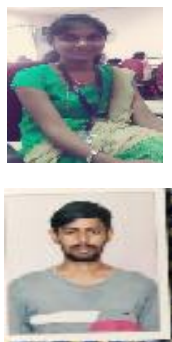

Dr.C K Gomathy an assistant professor in computer science and engineering at Sri Chandrasekharendra Saraswathi Viswa Mahavidyalaya Enathur, Kanchipuram,India. Her area of intrest lies in Software Engineering,Knowledge management, ,Software Quality

Thommandru Harshitha, Student, B.E Computer Science and Engineering, SCSVMV.

Posumanchi Vijay Nagendra Varma, Student, B.E Computer Science and Engineering, SCSVMV. 